\title{
Efficacy of Reflexology in Prevention of Post-Operative Nausea-Vomiting after General Surgery
}

\author{
Shweta Choudhary \\ AIIMS (All India Institute of Medical Sciences), New Delhi, India.
}

\begin{abstract}
How to cite this paper: Shweta Choudhary. (2021) Efficacy of Reflexology in Prevention of Post-Operative Nausea-Vomiting after General Surgery. International Journal of Clinical and Experimental Medicine Research, 5(2), 116-126.

DOI: $10.26855 /$ ijcemr.2021.04.005
\end{abstract}

Received: January 18, 2021

Accepted: February 20, 2021

Published: March 1, 2021

*Corresponding author: Shweta Choudhary, AIIMS (All India Institute of Medical Sciences), New Delhi, India. Email: drshwetachoudhary97@gmail.com

\begin{abstract}
In this study, we tried to find out the efficacy of reflexology in prevention of post-operative nausea and vomiting. Different types of methods have been used for prevention of post-operative nausea and vomiting. Conventional Method-Antiemetic-emeset $\quad(2-4 \quad \mathrm{mg})$. Promethazine $(12.5-25 \mathrm{mg})$, Metaclopromide (25-50 $\mathrm{mg})$ non-conventional method-acupressure, acupuncture, and reflexology. The purpose of the paper is to find the efficacy of reflexology in patients with postoperative nausea and vomiting after general surgery. The method is that 60 adult patients of general surgery from The All India Institute of Medical Science over the period of 2001-2005. Patients were divided randomly into two groups: Group I: Reflexology group (foot reflexology and required quantity of standard drugs) and Group II: Control group (standard quantity of standard drugs). Standard drugs included: Metaclopromide (25-50 mg), emeset (2-4 mg). Promethazine (12.5-25 mg). V and Nausea and vomiting score was measured at a time interval of $0 \mathrm{hr}$ (is time which patient as shifted to recovery room), $2 \mathrm{hrs}, 6 \mathrm{hrs}, 24 \mathrm{hrs.}$ 0, 1, 2, 3, numbering has been used for nausea and vomiting.
\end{abstract}

\section{Keywords}

Reflex Point, Pressure Mechanism, Receptors, Neuro, Electro, Chemical Transmission

\section{Introduction}

Reflexology is one of the most miraculous means of utilizing a natural healing method for maintaining the body in a post-operative condition. Reflexology is a non-pharmaceutical intervention. The body's vital life force circulates along pathways with an estimated 800 points on the body (see Figure 1). It is not necessary to know all of these points since the hand as well as the feet contain "reflex buttons", which are connected to all organs and glands. When these reflex centers are stimulated, they instantly send a surge of new vigor to the part of body they are connected to and with no side effects.

The use of reflexology has increased in Medical Care Recent reports include usage in birthing, OBGYN care, post surgical care, ICU, and patient support. The International Institute of Reflexology clearly states that it does not make any medical claims.

The physiological changes achieved with the application of pressure are based on the neurological relationship that exists between the skin and the nervous system. Whereas, a therapeutic effect can be achieved by stimulation at a distance from the arca where the pressure is applied. Reflexology believes that the body is reiterated or mirrored on the feet and hands and works within a zonal system, as introduced by Dr. William Fitzgerald. According to the 
zone theory, the body is divided into 10 equal longitudinal zones (five on the left side and five on the right side) running through the body from the top of the head to the tips of the toes. If there is congestion in any part of the body, the corresponding zone is affected. Using this theory, we apply direct pressure to any part of the affected zone to stimulate the entire zone. Dr. Riley supported the zone theory and his assistant, Eunice Ingham plotted the reflexes of all the body areas onto the feet, thus creating the foot map. The study of reflexology is based on anatomy and physiology of the human body. The principle of reflexology is founded on the understanding of how the nerves work what they mean to the human body.
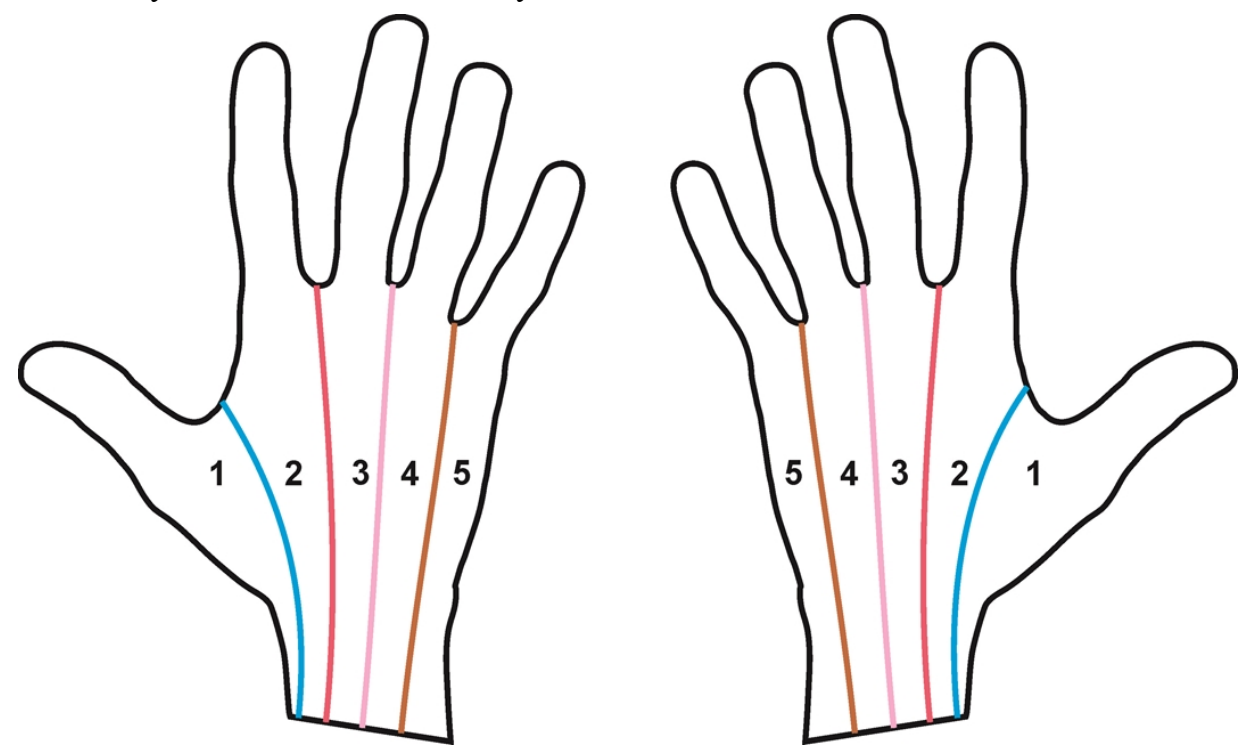

Figure 1. Zones of hand.

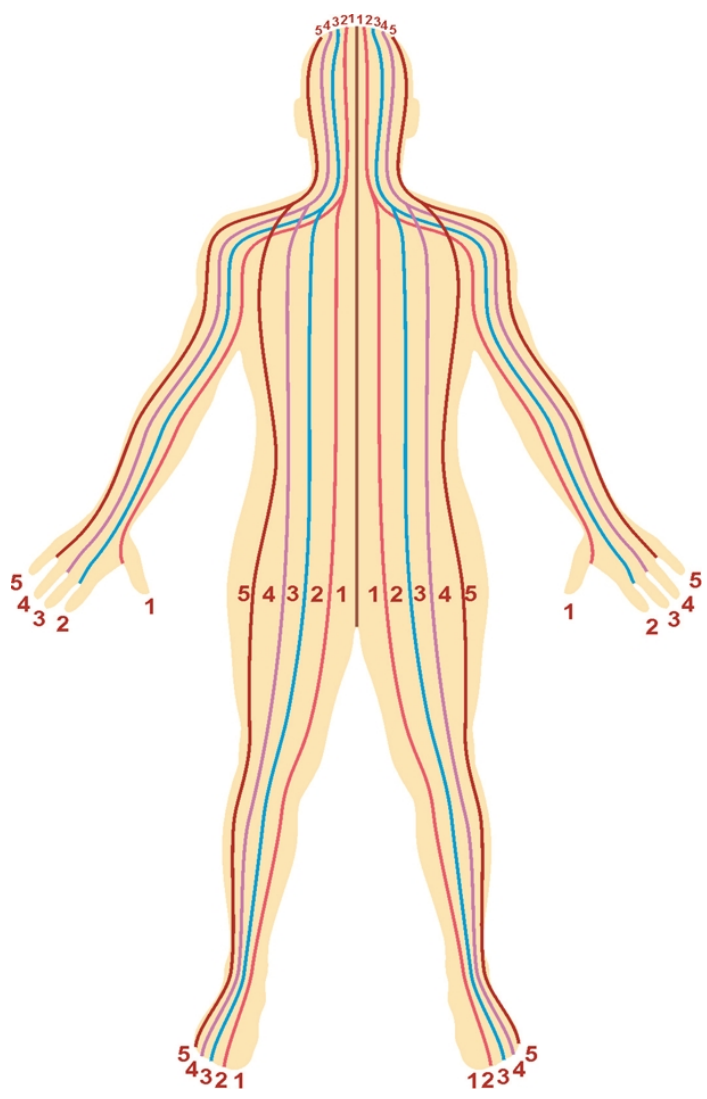

Figure 2. Zones of body. 


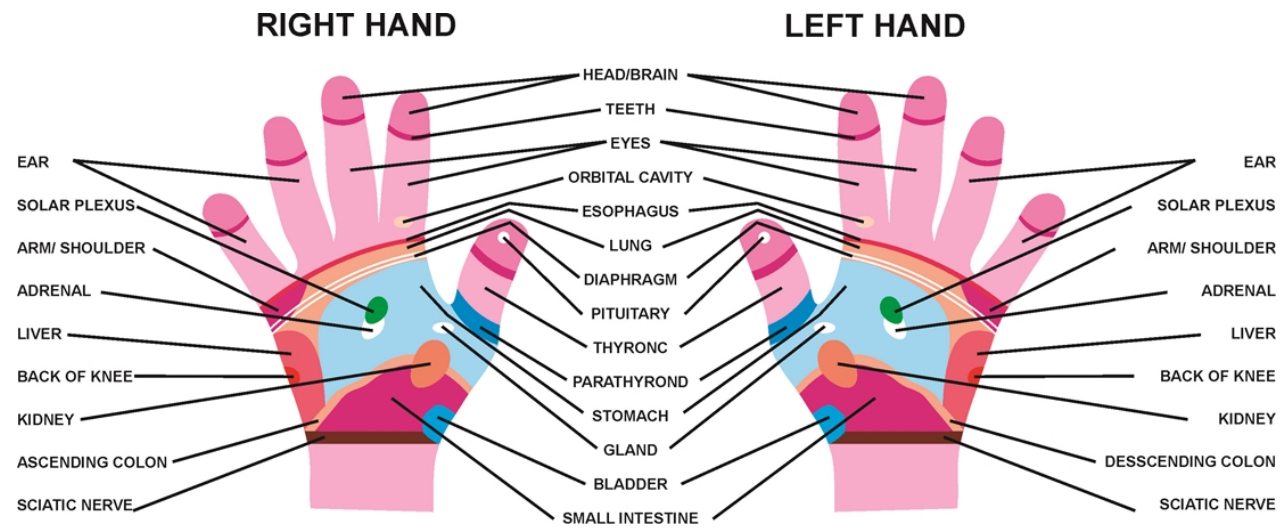

Figure 3. Hand reflexology map.

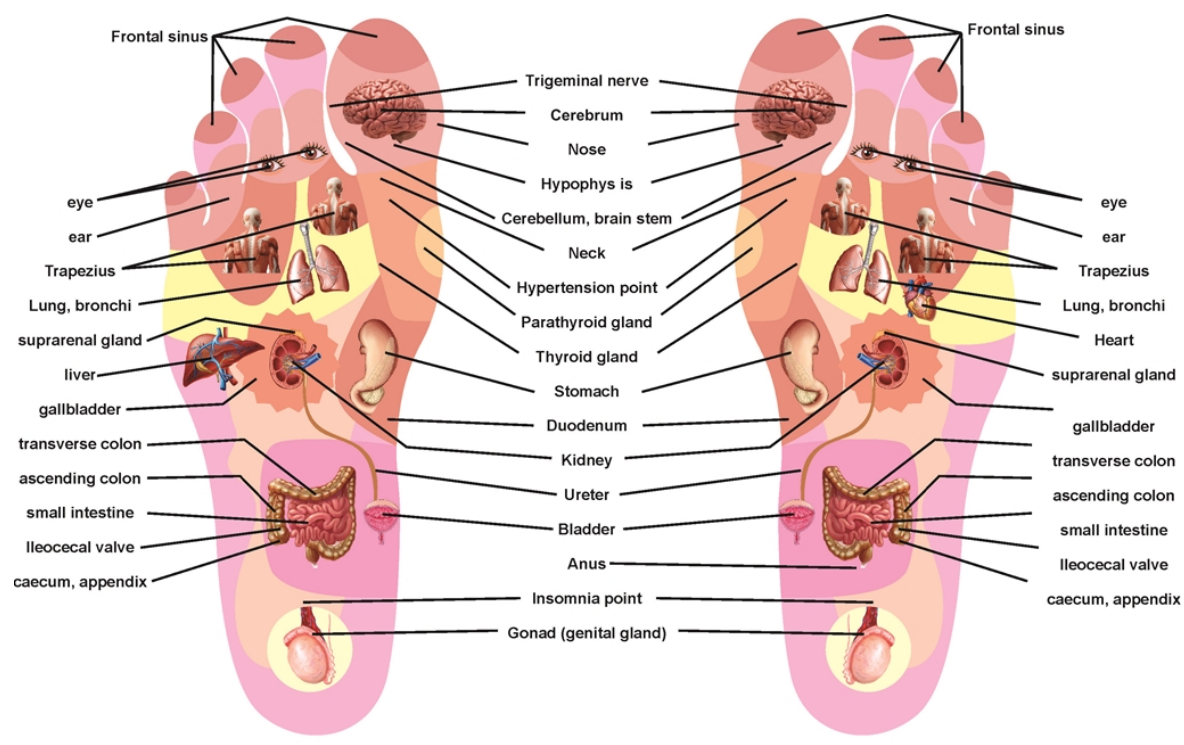

RIGHT FOOT

LEFT FOOT

Figure 4. Foot reflexology map.

\section{Theory of Reflexology}

There are over 7,200 nerve endings in each foot, which have an extensive interconnection with the central nervous system. These nerve endings are part of our sensory apparatus in which they sense pain and pressure, hot and cold, etc. Reflexology stimulates or fine-tunes this sensory apparatus and its neural pathways. Stress patterns are also manifested on the feet. There are many theories of reflexology, some of which are explained here. Applied Theory: The foot reflects the body's response to the stresses of gravity and movement. Blood and nerve supply theory. When muscles become tense, they press on the arteries causing sluggishness in circulation. This results in toxins in the blood, which would normally be excreted. At these deposits, needle shaped crystals settle in the extremities of the hands and feet. It is believed that these deposits interrupt some nerve impulses and cause dysfunction in the blood circulation. Reflexology applies pressure to break down the crystals and release them through the excretory systems.

\section{Post-Operative Nausea Vomiting After General Surgery}

Post-Operative Nausea and Vomiting (PONV) is one of the most common and distressing side effects after surgery due to anesthetics factors. It is estimated that $20 \%$ to $30 \%$ of adult patients will develop PONV. Researchers have reported an incidence of PONV of $25 \%$ to $55 \%$ following in in-patient surgery and from $8 \%$ to $47 \%$ in out-patient procedures.

Non-anesthetic factors responsible for PONV include age, gender, motion sickness, body habits, surgical site and post-operative feeding procedure. 


\section{Neuro-transmitter play important role in Nausea and vomiting}

Dopamine neurotransmitter (5 HT) at D2 receptor site is responsible for vomiting. While haloperidol or 5 HT3 receptor is antagonist.

Antiemetics activate $5 \mathrm{HT} 3$ receptor in $\mathrm{CTZ}$ portion of brain via vagus nerve.

Anesthesia activates dopamine.

Pressure stimulation on just below the meta-carple of index finger where the place of some specific neuro or electrical transmission activate the radial nerve path away through cervical pathways reach CTZ portion of the brain, and activate haloperidol or 5 HT3 receptors.

That is in acupressure reflexology and enti-emetic s way of action is different but target is same, can work in place of entiemetics so reflexology reduce the quantity of antiemetic after general surgery. It is explained further in diagram and data.

The physiological changes achieved with the application of pressure are based on the neurological relationship that exists between the skin and the nervous system. Whereas, a therapeutic effect can be achieved by stimulation at a distance from the arca where the pressure is applied. Reflexology believes that the body is reiterated or mirrored on the feet and hands and works within a zonal system, as introduced by Dr. William Fitzgerald. According to the zone theory, the body is divided into 10 equal longitudinal zones (five on the left side and five on the right side) running through the body from the top of the head to the tips of the toes. If there is congestion in any part of the body, the corresponding zone is affected. Using this theory, we apply direct pressure to any part of the affected zone to stimulate the entire zone. Dr. Riley supported the zone theory and his assistant, Eunice Ingham plotted the reflexes of all the body areas onto the feet, thus creating the foot map. The study of reflexology is based on anatomy and physiology of the human body. The principle of reflexology is founded on the understanding of how the nerves work what they mean to the human body.

Under most circumstances pain causes the greater amount of suffering, particularly after major surgeries. The specific area of central nervous system to which afferent nerve fiber pass determines the type of sensation. For example, if a pain nerve fiber is stimulated by heat, cold, touch, and pressure, the individual will experience only pain. Mainly anesthetic factors are responsible for PONV but other associate factors such as age, gender, type of surgery and atmosphere.

Receptor function-Specific neurotransmission or electrical transmission

Vomiting-It is a method/reflex action by which upper part of alimentary tract rids itself of its contents.

Physiology of PONV

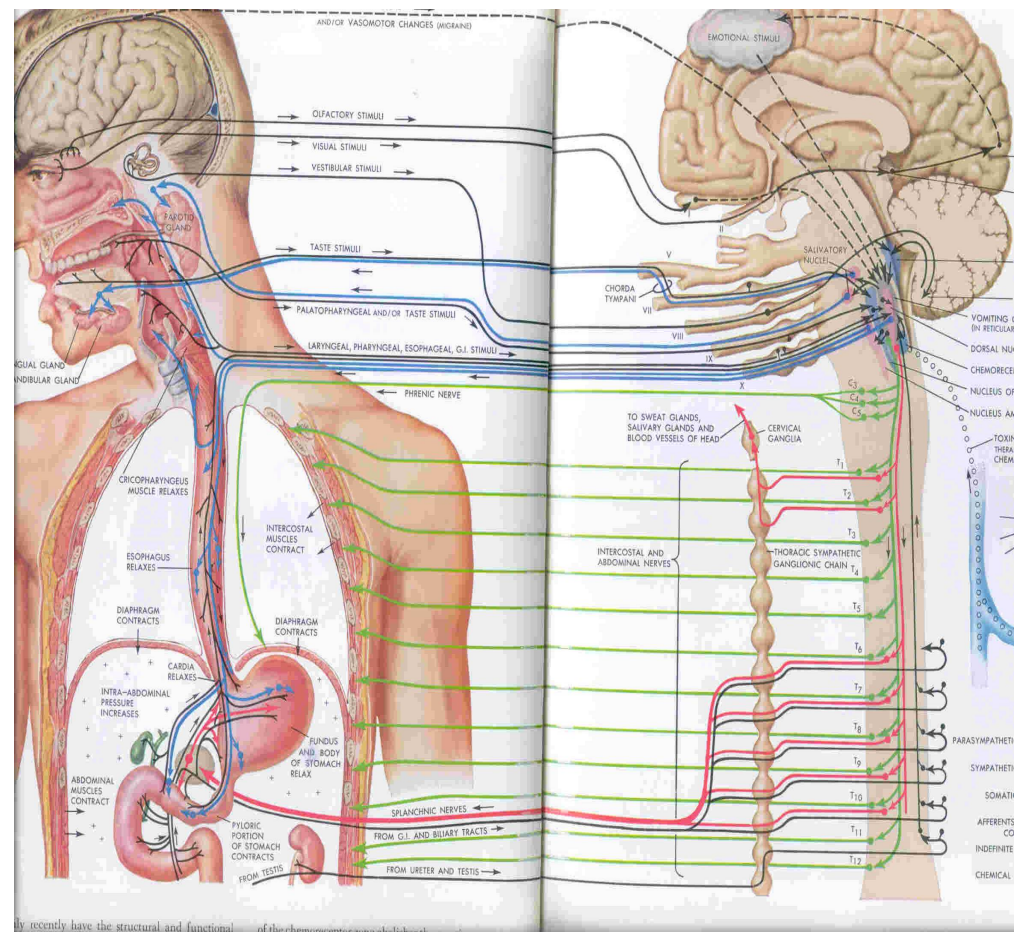

Figure 5. Physiology of PONV. 
First stimulation of chemo receptor in GI

Afferent nerve arises from abdominal spolanchnic and vagal nerves

Vestibule labyrinthine receptor cortex

Cerebral cortex and chemo receptor trigger zone postrema (part)

Dopamine receptor

(5 HT receptor is activator)

Histamine Ist

Haloperidal metaclopropromide and phenothiazine (5-HT3 antagonist)

Efferent branches

$5^{\text {th }}, 7^{\text {th }}, 9^{\text {th }}$ cranial nerves as well as vagus

And make a sympathetic trunk

Produce the complex and coordinating set of muscular contraction cardiovascular response and reverse peristalsis that characterizing vomiting vagus nerve play important role in mechanism of nausea and vomiting.

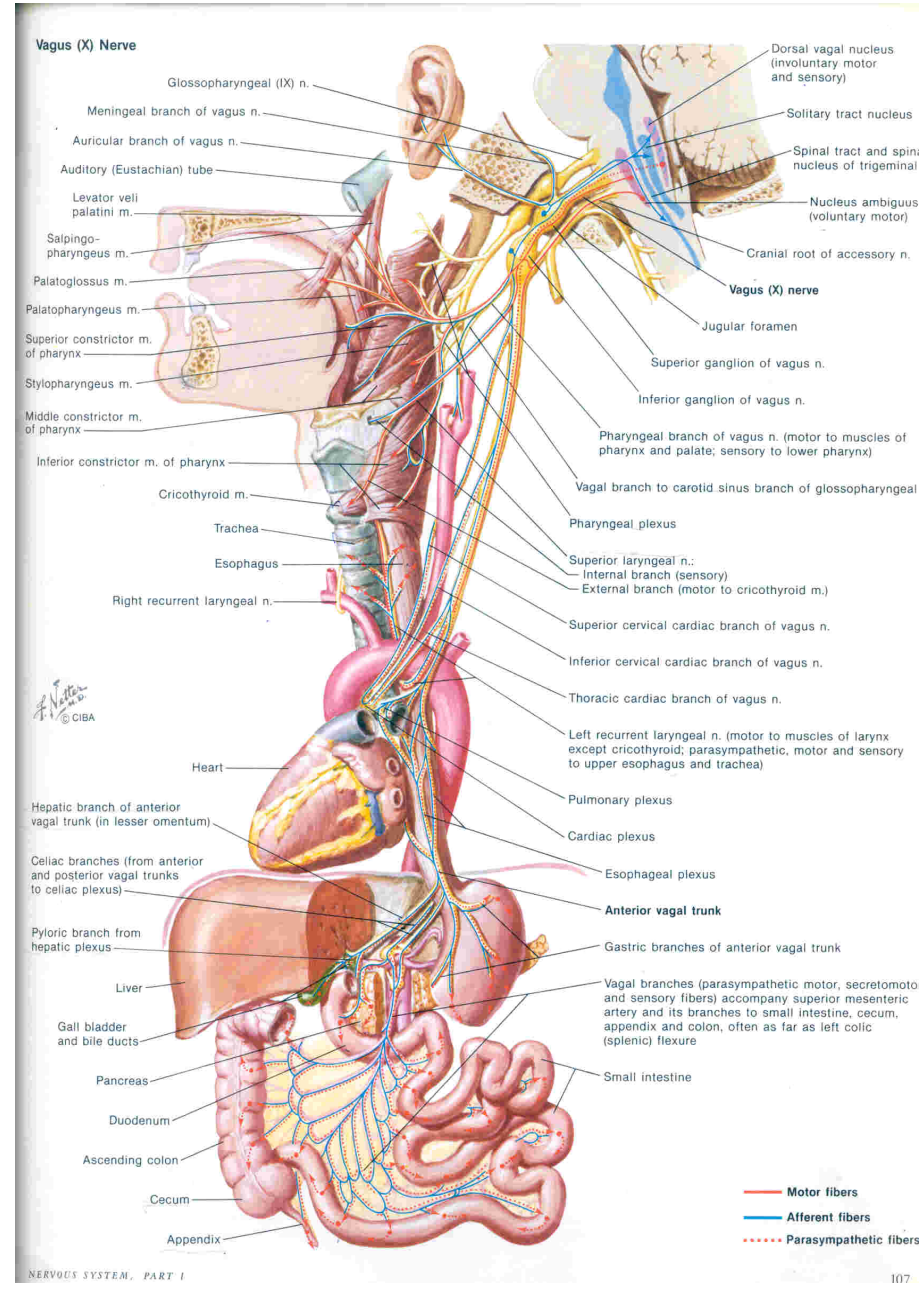

Figure 6. Vagus nerve's pathway. 
Radial nerve pathway-specific electro chemical or neurochemical receptors pass away through this pathway -goes to cervical reason and then reach CTZ portion of the brain and stimulate 5 HT-3 to dopamine receptor just like the action of antiemetic through vagus nerve pathway.

Vagus nerve pathway receptors are activated by antiemetics which activate Haloperidol (5 HT-3) receptor in CTZ portion of brain which block dopamine receptor.

Anesthetic factors mainly stimulate dopamine receptors which responsible for vomiting.

Radial nerve pathway receptors are activated by pressure stimulation (dig and backup technique) on just below the metacarple of the index finger.

Ways and process are different but target is same for anti emetics and pressure reflex.

\section{Pressure reflex path way}
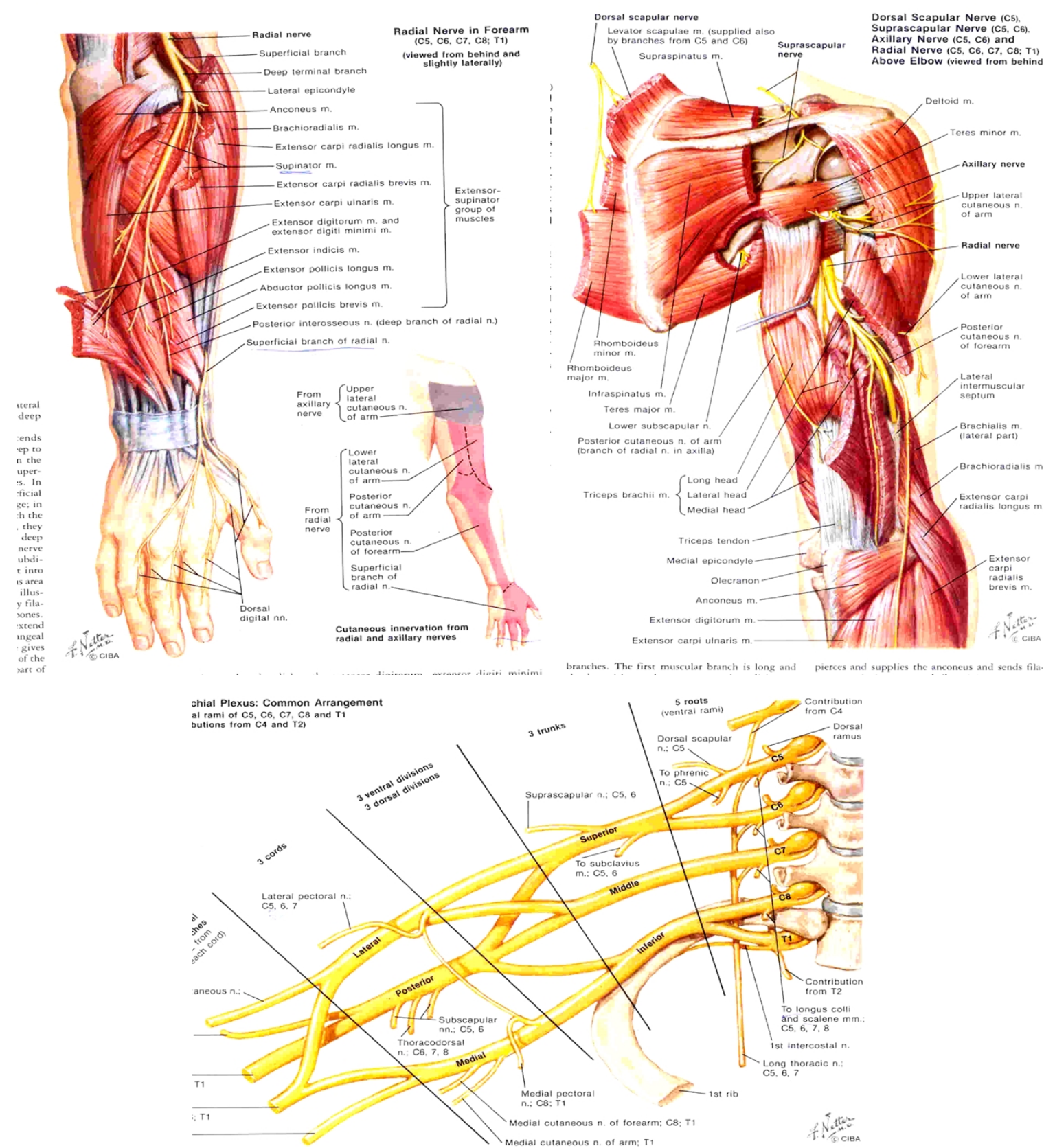

Figure 7. Radial nerve's pathway (transmission of receptors after stimulation on LI-3 point through radial nerve towards CTZ portion of brain). 


\section{Methods used in Prevention of Post-Operative nausea and vomiting:}

1. Conventional method - emeset (2-4 mg). Promethazine (12.5-25 mg), Metaclopromide (25-50 mg).

2. Non-conventional method-acupressure, acupuncture, and reflexology.

Method: Sixty adult patients were randomly divided into Group I (Reflexology group) and Group II (Control group).

Step I: Reflexology group (foot reflexology and the required quantity of standard drugs), $\mathrm{N}=32$ (12 males and 20 females);

Step II: Control group (standard quantity of standard drugs), $\mathrm{N}=28$ (12 males and 16 females). Emeset (2-4 mg). Promethazine (12.5-25 mg), Metaclopromide (25-50mg)

\section{Measurements were used in this study:}

1. Measurement of quantity and requirement of Antiemetics.

2. Measurement of nausea vomiting score.

1 - 0 -Free from nausea and vomiting.

2-Nausea.

3-Vomiting once and twice.

1-Sever vomiting.

Score was done at four time intervals in both groups at $0 \mathrm{hr}, 2 \mathrm{hrs}, 6 \mathrm{hrs}, 24 \mathrm{hrs}$; Zero hours as defined as the time patient was moved to recovery room.

It was noted that there was a decrease in the requirement and quantity of antiemetic s by reflexology therapy.

Technique-Hand Reflexology for vomiting and nausea.

To prevent and manage postoperative nausea and vomiting the thumb walking technique on index finger and thumb tip pressure on specific reflex point just below the metacarpal of index finger for 3-5 minute on the both hand of unconscious patient immediately at the end of operation.

\section{Method}

Group I compared with the control Group II.

Table A

Nausea vomiting score at $0 \mathrm{hr}$;

Nausea, vomiting score at $2 \mathrm{hrs}$;

Nausea vomiting score at $6 \mathrm{hrs}$;

Nausea vomiting score at $24 \mathrm{hrs}$.

Patients are divided into Group I (Reflexology group) and Group II (Control group). Step I: Reflexology group (foot reflexology plrs the required quantity of standard drugs), $\mathrm{N}=32$ (12 males and 20 females);

Step II: Control group (standard quantity of standard drugs), $\mathrm{N}=28$ (12 males and 16 females). Emeset (2-4 mg). Promethazine (12.5-25 mg), Metaclopromide (25-50 mg).

\section{Measurements were used in this study:}

1. Measurement of quantity and requirement of Antiemetics.

2. Measurement of nausea vomiting score.

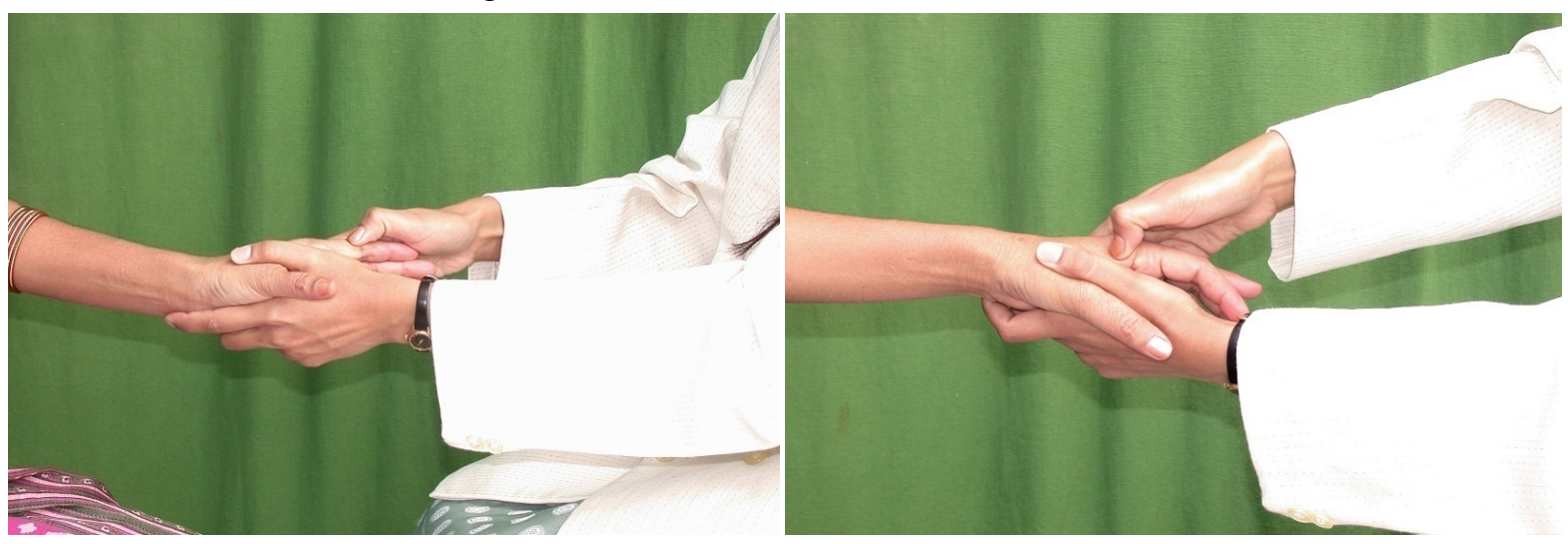

Figure 8. Technique-Finger Working Technique, Finger walking, Finger rotary pressure. 
Technique-Hand Reflexology for vomiting and nausea.

To prevent and manage postoperative nausea and vomiting the thumb walking technique on Index finger and thumb tip pressure on specific reflex point just below the metacarpal of index finger for 3-5 minute on the both hand of unconscious patient immediately at the end of operation.

\section{Group I compared with the control Group II.}

Table A

Nausea vomiting score at $0 \mathrm{hr}, \mathrm{P}=0.001$;

Nausea, vomiting score at $2 \mathrm{hrs}, \mathrm{P}=0.001$;

Nausea vomiting score at $6 \mathrm{hrs}, \mathrm{P}=0.001$;

Nausea vomiting score at $24 \mathrm{hrs}, \mathrm{P}=0.72$.

Table B

Distribution of antiemetic at $0 \mathrm{hr}, \mathrm{P}=0.001$;

Distribution of antiemetic at $2 \mathrm{hrs}, \mathrm{P}=0.001$;

Distribution of antiemetic at $6 \mathrm{hrs}, \mathrm{P}=0.001$;

Distribution of antiemetic at $24 \mathrm{hrs}, \mathrm{P}=0.001$.

Table 1. Nausea and vomiting score at $0 \mathrm{hrs}$

\begin{tabular}{|c|c|c|}
\hline Nausea and vomiting & Reflexology (Group I) & Control (Group II) \\
\hline A. No & 24 & 3 \\
\hline B. Yes & 8 & 25 \\
\hline
\end{tabular}

$\mathrm{P}=0.001$ Description of nausea vomiting score

\begin{tabular}{|c|c|c|c|c|}
\hline score & 0 & 1 & 2 & 3 \\
\hline Reflexology Group-I & 24 & 4 & 4 & \\
\hline Control Group-II & 3 & 11 & 13 & 1 \\
\hline
\end{tabular}

Table 2. Nausea vomiting score at 2 hrs

\begin{tabular}{|c|c|c|}
\hline Nausea and voniting & Reflexology (Group I) & Control (Group II) \\
\hline A.No & 19 & 3 \\
\hline B.Yes & 13 & 25 \\
\hline
\end{tabular}

$\mathrm{P}=0.001$ Description of nv scores

\begin{tabular}{|c|c|c|c|c|}
\hline score & 0 & 1 & 2 & 3 \\
\hline Reflexology Group-I & 19 & 11 & 2 & \\
\hline Control Group-II & 3 & 14 & 8 & 3 \\
\hline
\end{tabular}

Table 3. Nausea and vomiting Score at 6 hrs

\begin{tabular}{|c|c|c|}
\hline Nausea and vomiting & Reflexology (Group I) & Control (Group II) \\
\hline A. No & 25 & 3 \\
\hline B. Yes & 7 & 25 \\
\hline
\end{tabular}

$\mathrm{P}=0.001$. Descriptions of nv score.

\begin{tabular}{|c|c|c|c|c|}
\hline score & 0 & 1 & 2 & 3 \\
\hline Reflexology Group-I & 25 & 7 & & \\
\hline Control Group-II & 3 & 12 & 12 & 1 \\
\hline
\end{tabular}


Table 4. Nausea and vomiting score at $24 \mathrm{hrs}$

\begin{tabular}{|c|c|c|}
\hline Nausea and voniting & Reflexology (Group I) & Control (Group II) \\
\hline A. No & 22 & 18 \\
\hline B. Yes & 10 & 10 \\
\hline
\end{tabular}

$\mathrm{P}=0.72$ Description of nv scores.

\begin{tabular}{|c|c|c|c|c|}
\hline score & 0 & 1 & 2 & 3 \\
\hline Reflexology Group-I & 22 & 3 & 6 & 1 \\
\hline Control Group-II & 18 & 8 & 2 & \\
\hline
\end{tabular}

Distribution of Ant emetics at $0 \mathrm{hr}$.

Table 5. Distribution of Ant emetics at $0 \mathrm{hr}$

\begin{tabular}{|c|c|c|}
\hline Ant emetic used & Reflexology (Group I) & Control (Group II) \\
\hline A. No & 29 & 0 \\
\hline B. Yes & 3 & 28 \\
\hline
\end{tabular}

$\mathrm{P}=0.001$

Table 6. Distribution of Ant emetics at 2 hrs

\begin{tabular}{|c|c|c|}
\hline Ant emetic used & Reflexology (Group I) & Control (Group II) \\
\hline A. No & 17 & 0 \\
\hline B. Yes & 15 & 28 \\
\hline
\end{tabular}

$\mathrm{P}=0.001$

Table 7. Distribution of Ant emetics at 6 hrs

\begin{tabular}{|c|c|c|}
\hline Ant emetic used & Reflexology (Group I) & Control (Group II) \\
\hline A. No & 20 & 0 \\
\hline B. Yes & 12 & 28 \\
\hline
\end{tabular}

$\mathrm{P}=0.001$.

Table 8. Distribution of Ant emetics at $24 \mathrm{hrs}$

\begin{tabular}{|c|c|c|}
\hline & Reflexology (Group I) & Control (Group II) \\
\hline A. No & 25 & 0 \\
\hline B. Yes & 7 & 28 \\
\hline
\end{tabular}

$\mathrm{P}=0.001$. Fischer's exact test is used in every statistical analysis.

The result is that Group I showed a significant decrease and absolutely significance in decreasing of nausea and vomiting scores and the requirement and quantity of drugs in Group I as compared to Group II. The discussion is that under the most circumstances nausea vomiting and pain causes, the greater amount of suffering. Particularly, after general surgery, the effect of foot reflexology causes a very significant reduction of nausea vomiting score and antiemetics in Group I in comparison with Group II in post-operative patients of general surgery.

\section{Discussion}

Postoperative nausea and vomiting (PONV) is a complication affecting between $20 \%$ and $40 \%$ of all surgery patients, with high-risk patients experiencing rates of up to $80 \%$. Recent studies and publications have shed light on the uses of alternative treatment for PONV through their modulation of endogenous opioid neuropeptides and neurokinin ligands. In addition to reducing PONV, hypnosis was reported to be useful in attenuating postoperative pain and anxiety, and contributing to hemodynamic stability. Music therapy has been utilized to deepen the sedation level and decrease patient anxiety, antiemetic and analgesic requirements, hospital length of stay, and 
fatigue. Isopropyl alcohol and peppermint oil aromatherapy have both been used to reduce postoperative nausea. With correct training in traditional Chinese healing techniques, acupuncture (APu) at the P6 acupoint has also been shown to be useful in preventing early PONV, postdischarge nausea and vomiting, and alleviating of pain. Electro-acupuncture $(\mathrm{EAPu})$, as with $\mathrm{APu}$, provided analgesic and antiemetic effects through release and modulation of opioid neuropeptides. These non-pharmacological modalities of treatment contribute to an overall patient wellbeing, assisting in physical and emotional healing. In this study, we have seen also efficacy of reflexology and result is very satisfactory. Our aim do not compare to other therapy or treatment but relieve of patients from problem.

Need of further research to find out the physic-chemical study of reflexology or related reflex points.

\section{References}

[1] Bill KM, Dundee JW. (1988). Acupressure for postoperative nausea and vomiting. Br J clin pharpharmacol, 26 , p. 225.

[2] Bailey PL, Steisand JB, Pacen NL, Bubbers SJM, East KA, Mulder S, Stanley TH. (1990). Transdermal scopolamine reduces nausea vomiting after outpatient laproscopy. Anesthesiology, 72: 977-980.

[3] Ber van den AA, lambourne A, clayburn PA. (1989). The oculo-emetic reflex, a rationalization of postopthalmic anaesthesia vomiting. Anaesthesia, 44110-117.

[4] Bonica JJ, Crepps W, Monk B, Bennet B. (1958). Postanesthetic nausea, retching and vomiting; evalution of cyclizine marezine suppositories for treating. Anesthesiology, 19: 532-540.

[5] Burtles R, Peckett BW. (1957). Postoperative vomiting: some factors affecting its incidence. British Journal of Anesthesia 29, 114-123.

[6] Cailian Lin. (1998). "Clinical observation on treatment of 40 cases of uroschesis with reflexology." 1998 China Reflexology Symposium Report, China Reflexology Association, Beijing, pp. 52-53.

[7] Caplin D, Smith C. (1955). A comparison of the anti-emetic effects of dimenhydrinate, promethazine hydrochloride and chloropromazine following anaesthesia. Canadian Anesthetists Society Journal, 2: 193-197.

[8] Dundee JW, Assaf RAE, Loan WB, Morrison JD. (1975). A comparison of the efficacy of cyclizine and perphenazine in reducing the emetic effects of norphine and pethidene. Br $\mathrm{j}$ clin pharmacol., 2: 81-5.

[9] Duan shuang Feng. (1993). Foot reflexology in neurosism; clinical observation of 20 cases. Presented at the China reflexology symposium in Beijing (July 1993). Reflexology research reports 9 Association of reflexologists. $2^{\text {nd }}$ edition.

[10] Gowri Motha and Dr. Jane Mc. Grath. (2000). Forest Gate, London, England the effects of reflexology on labour outcome, Grealish, L. lomasney, A. Whiteman, B., et al., foot massage: A nursing intervention to modify the distressing symptoms of pain and nausea inpatients hospitalized with cancer, Cancer Nurse, June: 23. (30: 237-43, on-line review: "reflexology used for cancer patients," Internet healthy library, October 11, 2000).

[11] Jenkins LC, Lahay D. (1971). Central mechanism of vomiting related to catecholmine responses: Anaesthetic implications. Canadian Anaesthetists Society Journal, 18: 434-441.

[12] Klockgether-Radke A, Neumann S, Neumann P, Braun U, Miiblendyck H. (1997). Ondansetron, droperidol and their combination for the prevention of post-operative of post-operative vomiting in children. Eur J Anesthesiol., 14: 362-7.

[13] Knapp MR, Beecher HK. (1965). Post anesthetic nausea, vomiting and retching. Journal of the American Medical association, 160: 376-385.

[14] Lim KS, Lim BL, Tee CS, Vengadasalam D. (1991). Nausea and vomiting after termination of pregnancy as day surgery case: Comparison of 3 different doses of droperidol and metaclopromide as anti-emetic prophylaxis. Singapore Med J., 32 : 342-3.

[15] Lin DM, Furst SR, Rodarte A. (1992). A double-blinded comparison of metoclopramide and droperidol for prevention of emesis following Strabismus surgery. Anesthesiology, 76: 357-361.

[16] Madej TH, Simpson KH. (1986). Comparison of the use of domperidone. Droperidol and metoclopramide in the prevention of nausea and vomiting following major gynaecological surgery. British Journal of Anaesthesia, 58: 884-887.

[17] The Effect of Reflexology on Chemotherapy-induced Nausea ... www.ncbi.nlm.nih.gov > pmc > articles > PMC5473096 Nausea and vomiting could be observed in $40 \%-70 \%$ of cancer patients during ... and a posttest was applied to the patients 24 hours after each reflexology ...

[18] The Effect of Reflexology on Chemotherapy-induced ... www.researchgate.net > ... >

[19] The efficacy of reflexology: Systematic review | Request PDF www.researchgate.net.

[20] Effect of Foot Massage on Patients with Chemotherapy Induced ...europepmc.org > article > med. Journal of Caring Sciences, 18 Aug 2020, 9(3): 120-124.

[21] The effectiveness of aromatherapy, massage and reflexology ...europepmc.org > articles > bin > supplementary_materials.

[22] The effectiveness of aromatherapy, massage and reflexology ...journals.sagepub.com > doi > full. Oct 29, 2019—New clinical 
recommendations cannot be made based on current evidence. To help provide more definitive trial findings, it may be useful first to ...by B Candy $\cdot 2020$.

[23] Auriculotherapy to control chemotherapy-induced nausea and ... systematicreviewsjournal.biomedcentral.com > articles.

[24] Auriculotherapy is a type of acupuncture and may be a low-cost and safe antiemetic ... The outcomes to be evaluated are nausea and vomiting: in acute, ... carried out to evaluate the effectiveness of acupressure in CINV control, and ... immediately after the final analysis, in order to enable new studies to be ...by RNR Melo $\cdot 2019$.

[25] Education, Pregnancy, Quality of life, Relaxing - JCDR jcdr.net > article_fulltext.

[26] A Randomized Clinical Trial of Caregiver-Delivered. www.jpsmjournal.com > article > fulltext.

[27] Journals Containing Peer-Reviewed Research-Irish. https://www.reflexology.ie/journals-containing-peer-reviewed-research-1.

[28] A Randomized Clinical Trial of Caregiver-Delivered. https://pubmed.ncbi.nlm.nih.gov/28743659. Purpose: The objective of this study was to determine the effects of a home-based reflexology intervention delivered by a friend/family caregiver compared with attention control on health-related quality of life of women with advanced breast cancer undergoing chemotherapy, targeted and/or hormonal therapy. Methods: Patient-caregiver dyads $(\mathrm{N}=256)$ were randomized to four weekly reflexology.

[29] www.nationalreflexology.ie/articles. Reflexology is a type of acupressure or massage that focuses on the feet. The idea is that by stimulating points on the feet, one can improve the health of corresponding parts of the body, including various organs and the breasts. Reflexology has been used as a healing modality for thousands of years in Asia.

[30] Determination of Efficacy of Reflexology in Managing. https://www.hindawi.com/journals/ecam/2014/843036.

[31] Is There Science to Support Reflexology? https://www.massagemag.com/science-reflexology-research-86595. 